\title{
Flavin doesn't put all oxygens in one basket
}

DOI:

10.1038/s41589-020-0523-z

\section{Document Version}

Accepted author manuscript

Link to publication record in Manchester Research Explorer

\section{Citation for published version (APA):}

Leys, D., \& Scrutton, N. S. (2020). Flavin doesn't put all oxygens in one basket. Nature chemical biology, 16(5), 485-486. https://doi.org/10.1038/s41589-020-0523-z

\section{Published in:}

Nature chemical biology

\section{Citing this paper}

Please note that where the full-text provided on Manchester Research Explorer is the Author Accepted Manuscript or Proof version this may differ from the final Published version. If citing, it is advised that you check and use the publisher's definitive version.

\section{General rights}

Copyright and moral rights for the publications made accessible in the Research Explorer are retained by the authors and/or other copyright owners and it is a condition of accessing publications that users recognise and abide by the legal requirements associated with these rights.

\section{Takedown policy}

If you believe that this document breaches copyright please refer to the University of Manchester's Takedown Procedures [http://man.ac.uk/04Y6Bo] or contact uml.scholarlycommunications@manchester.ac.uk providing relevant details, so we can investigate your claim.

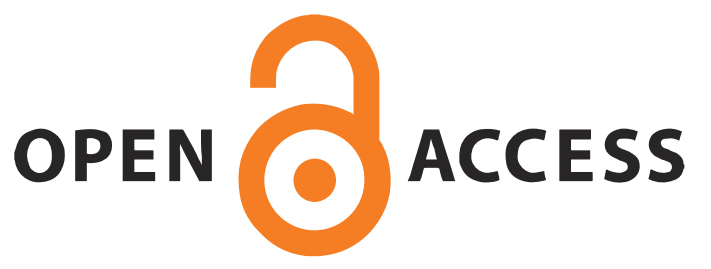




\section{ENZYMOLOGY}

Flavin doesn't put all oxygens in one basket

David Leys and Nigel S. Scrutton

\section{Standfirst:}

Oxygen activation mechanisms catalysed by flavin cofactors are established for electron transfer (oxidases) and C4a covalent flavin-oxygen adduct formation (oxygeninserting monooxygenases). A new paradigm for oxygen insertion involving a flavin-N5aminoperoxide intermediate has now been discovered in selected flavin-dependent monooxygenases.

Text:

Dioxygen activation is tightly controlled in biology. Selected biological cofactors, including flavins and some metals, can activate dioxygen to enable oxygen reduction (oxidases), or oxygen atom insertion (monooxygenases) into organic substrates. Mechanistic paradigms for flavin-catalysed oxygen activation are firmly established in the literature, and have been studied extensively over several decades ${ }^{1}$. Flavoprotein oxidases catalyse rapid reduction of dioxygen by electron transfer to form hydrogen peroxide; by contrast, flavoprotein monooxygenases form covalent flavin-C4a-(hydro)peroxide intermediates that promote oxygen atom insertion into organic substrates. Both oxidases and monooxygenases activate dioxygen using the reduced flavin cofactor $\left(\mathrm{FI}_{\text {red }}\right)$, which is reflected in widely accepted mechanistic schemes (Figure 1). In this issue, Matthews et al. now report the surprising finding that oxygen insertion into organic substrates can also occur in selected flavoprotein monooxygenases using a newly discovered flavin-N5-aminoperoxide adduct intermediate ${ }^{2}$.

Flavins are intrinsically versatile. As free cofactors and during biological catalysis, they engage in a wide range of chemical reactions including long-range electron transfer, oxygen activation, photochemistry and reductive chemistry. ${ }^{3}$ Despite a long history for flavin chemistry, unprecedented reactions continue to emerge. Notable recent discoveries include flavin prenylations that support enzyme-catalysed (de)carboxylation; photochemical activation of flavin for decarboxylation ${ }^{5}$ and stereoselective cyclizations ${ }^{6}$; formation of superoxidised flavin N5-oxides for the 4-electron oxidation of polyketides ${ }^{7}$ and flavin N5-centred C1 transfer reactions ${ }^{8}$. This catalytic and chemical versatility of flavin expands the utility of flavoenzymes as (photo)biocatalysts, broadening the reaction types available to biocatalysis toolkits. It also extends the capabilities of natural enzymes to engage in a wide range of cellular transformations, including light emission and lightdependent signalling. ${ }^{9,10}$ No doubt further surprises will come to light to illustrate yet more chemical versatility, especially as we continue to discover new flavoenzymes and engineer them towards novel function. That selected flavoproteins can use a flavin-N5aminoperoxide adduct for monooxygenation is especially noteworthy. This finding breaks with dogma; flavoprotein monooxygenase reactions were inferred to progress exclusively through a covalent flavin-C4a-(hydro)peroxide intermediate prior to this discovery.

The work of Matthews et al extends a previous study of flavin N-oxide identification in the enzyme $\mathrm{EnCM}^{7}$ by showing that the N5 atom can also support flavin-N5- 
aminoperoxide formation. The authors investigated RutA as a model enzyme, which alongside two other enzymes DszA and HcbA1 - had previously been suggested to catalyse substrate $\mathrm{C}$-heteroatom cleavage, with formation of a flavin N5-oxide coproduct. The original catalytic mechanism had invoked use of C4a-flavin-hydroperoxide in-line with current dogma relating to flavin-dependent monooxygenases. The study now reported in this issue fundamentally challenges this assertion and suggests monooxygenation can occur through an alternative flavin-N5-aminoperoxide intermediate. ${ }^{2}$ Matthews et al used $\mathrm{O}_{2}$ pressurised $\mathrm{X}$-ray crystallography to show $\mathrm{O}_{2}$-binding close to the $\mathrm{N} 5$ atom of the flavin mononucleotide (FMN) isoalloxazine ring at high pressure, while electron density for the modelled $\mathrm{O}_{2}$ was less clear at lower pressures and absent under anaerobic conditions. Unusually, the proposed hydrophobic $\mathrm{O}_{2}$-binding site was found on the re-side of the flavin, while the RutA substrate uracil binds on the opposite si-face. There are therefore profound implications of this mode of binding: following formation of the flavin-N5-aminoperoxide intermediate, flavin $\mathrm{N} 5$-inversion is needed to position the reactive peroxide species close to the acceptor uracil bound on the si-face of FMN. Computations showed a small free energy barrier for N5-inversion and revealed near attack conformers for O-atom insertion into uracil. Overall, this new reaction mechanism was consistent with detailed DFT computations, mutagenesis and rapid mixing spectroscopy studies. Furthermore, the authors showed that the proposed $\mathrm{O}_{2}$-binding pocket is conserved in closely related group $\mathrm{C}$ flavin-dependent monooxygenases, but not in other classes of flavoprotein monooxygenase, indicating that this mechanism is likely conserved in other enzymes, but not across the entire flavin-dependent monooxygenase family.

Direct observation of flavin-peroxide adducts is non-trivial, and the work of Matthews et al infers existence of the presumably highly unstable N5-aminoperoxide species $^{2}$. Unlike the canonical C4a-(hydro)peroxide-based pathway, the N5-peroxide mediated oxygen insertion does not occur with formal oxidation of the product, yielding the 4-electron oxidized flavin N5-oxide instead. The redox neutral C-X bond breakage catalysed by RutA/DszA and HcbA1 therefore mimics a hydrolysis reaction and requires four electrons to return flavin to the reduced starting state. The inherent chemical repertoire associated with N5-oxidative chemistry and to what extent Nature makes use of this remains unclear. The future will tell whether it can mimic the wealth of C4a-based transformations.

\section{Authors:}

David Leys and Nigel S. Scrutton, Manchester Institute of Biotechnology and Department of Chemistry, School of Natural Sciences, The University of Manchester, Manchester M1 7DN, United Kingdom

\section{Email: nigel.scrutton@manchester.ac.uk; david.leys@manchester.ac.uk}

The authors declare no competing financial interests.

\section{References:}

1. Romero, E., Castellanos, J. R. G., Gadda, G., Fraaije, M. \& Mattevi, A. Same substrate, many reactions: oxygen activation in flavoenzymes. Chem Rev. 118, 1742 (2018). 
2. Matthews, A., Saleem-Batcha, R., Sanders, J. N., Stull, F., Houk, K. N. and Teufel, R. Aminoperoxidase adducts expand the catalytic repertoire of flavin monooxygenases. Nat. Chem. Biol. https://doi.org/10.1038/s41589-020-0476-2

3. Leys, D. \& Scrutton, N. S. Sweating the assets of flavin cofactors: new insight of chemical versatility from knowledge of structure and mechanism. Curr. Opin. Struct. Biol. 41, 19-26 (2016)

4. Payne, K. A. P. et al. New cofactor supports $\alpha, \beta$-unsaturated acid decarboxylation via 1,3-diploar cycloaddition. Nature 522, 497-501 (2015)

5. Sorigué et al. An algal photoenzyme converts fatty acids to hydrocarbons. Science 357, 903-907 (2017)

6. Black, M. J. et al. Asymmetric redox-neutral radical cyclization catalysed by flavindependent 'ene'-reductases. Nat. Chem. 12, 71-75 (2020)

7. Teufel, R. et al. Flavin-mediated dual oxidation controls an enzymatic Favorskii-type rearrangement. Nature 503, 552-556 (2013)

8. Mishanina, T. V. et al. An unprecedented mechanism of nucleotide methylation in organisms containing thyX. Science 351, 507-510 (2016)

9. Conrad, K. S., Manahan, C. C., Crane, B. R. Nat. Chem. Biol. 10, 801-809 (2014)

10. Kutta, R. J., Archipowa, N. \& Scrutton, N. S. Phys. Chem. Chem. Phys. 20, 2876728776 (2018)

Figure 1. Schematic overview of the flavin mediated $\mathrm{O}_{2}$-reduction process. The enzyme can control access to the reactive C4a-N5 locus, and stabilize/affect the properties of any flavoperoxides formed. While classical mono-oxygenases (in blue) operate via a C4a(hydro)peroxy intermediate (giving rise to a wide range of reactions), Matthews et al. reveal a subset of these enzymes (in green) operate via the N5-peroxide instead. In the latter case, crystal structures in complex with oxygen reveal the active site favours N5-peroxide formation, leading to the ability for redox-neutral C-X cleavage reactions. The ensuing N5oxide flavin will require 4-electron reduction to return to the flavin dihydroquinone state $(\mathrm{FI}$ red). 